\title{
The role of wind in hydrochorous mangrove propagule dispersal
}

\author{
T. Van der Stocken ${ }^{1,2, *}$, D. J. R. De Ryck ${ }^{1,2, *}$, T. Balke ${ }^{3}$, T. J. Bouma ${ }^{3,4}$, F. Dahdouh-Guebas ${ }^{1,2}$, and N. Koedam ${ }^{1}$ \\ ${ }^{1}$ Laboratory of Plant Biology and Nature Management, Vrije Universiteit Brussel, Pleinlaan 2, 1050 Brussels, Belgium \\ ${ }^{2}$ Laboratory of Systems Ecology and Resource Management, Université Libre de Bruxelles, Av. F.D. Roosevelt 50, CPI 169, \\ 1050 Brussels, Belgium \\ ${ }^{3}$ Deltares, PO Box 177, 2600 MH Delft, the Netherlands \\ ${ }^{4}$ Royal Netherlands Institute for Sea Research (NIOZ-Yerseke; former NIOO-CEME), P.O. Box 140, 4400 AC Yerseke, \\ the Netherlands \\ *These authors contributed equally to this work.
}

Correspondence to: T. Van der Stocken (tvdstock@ vub.ac.be)

Received: 18 December 2012 - Published in Biogeosciences Discuss.: 22 January 2013

Revised: 30 April 2013 - Accepted: 6 May 2013 - Published: 3 June 2013

\begin{abstract}
Although wind has been recognized to be an important factor in the dispersal of hydrochorous mangrove propagules, and hence in the quantification of (meta)population dynamics, the species-specific sensitivity to wind effects has not been studied. We combined observations from a controlled experiment (flume tank) and in situ experiments to understand wind and water current contributions to dispersal potential as well as to estimate real dispersal ranges due to immediate response to tidal currents (two outgoing tides). This was done for 4 species with propagules differing in morphological and buoyancy properties (i.e. Rhizophora mucronata, Ceriops tagal, Heritiera littoralis and Xylocarpus granatum). The flume experiments revealed that the influence of wind depends on the density of a propagule (and hence its buoyancy characteristics) and that typical morphological characteristics of the dispersal unit are additionally important. H. littoralis propagules were influenced most, because on the one hand their low density $\left(613.58 \mathrm{~g} \mathrm{~L}^{-1}\right.$; $n=10)$ enables them to float on top of the water surface, and on the other hand their "sailboat-like" structure provides a relatively large surface area. The $X$. granatum fruits appeared to be the least influenced by ambient wind conditions, explained by the smooth surface and spherical shape of which, because of the fruit's high density $\left(890.05 \mathrm{~g} \mathrm{~L}^{-1} ; n=1\right)$, only a small part sticks above the water surface. Although the seeds of $X$. granatum are of a similar size class than $H$. littoralis propagules, they are (like the $X$. granatum fruits) largely submerged due to their high density $\left(870.66 \mathrm{~g} \mathrm{~L}^{-1}\right.$; $n=8$ ), hence catching less wind than $H$. littoralis propag-
\end{abstract}

ules. The influence of wind on the dispersal of the horizontally floating $C$. tagal and $R$. mucronata dispersal units was strong, comparable to that of $H$. littoralis propagules. A differential effect of wind was found within elongated propagules, which directly follows from the floating orientation of the propagules. While the dispersal path of vertically floating propagules was influenced by the strength and direction of the water currents and to a lesser extent by ambient wind conditions, the dispersal path of horizontally floating propagules was influenced by both strength and direction of the water currents and prevailing wind forces. To validate the flume results, propagules of $C$. tagal and $R$. mucronata were released during outgoing tide in a tidal creek in Gazi Bay (Kenya), followed by observation of their dispersal distance and direction, while knowing the actual dominant wind direction. In line with the flume results, this study showed that wind plays an important role in the dispersal distance of the propagules. The present study provides important mechanistic insight into the effect of wind on hydrochorous mangrove propagule dispersal, thereby yielding an essential step towards the construction and optimization of (particle-based) hydrodynamic dispersal models.

\section{Introduction}

A series of publications have stressed the importance of dispersal in the evolution of plant population structure and composition (e.g. Duke et al., 1998; Cain et al., 2000; 
Nathan and Muller-Landau, 2000; Bowne and Bowers, 2004; Caswell et al., 2003; Nathan et al., 2003; Clobert et al., 2012), where other reports emphasized the fundamental need to study long-distance dispersal as a crucial mechanism for understanding and predicting the adaptability of species to cope with environmental and climate change (e.g. Pitelka et al., 1997; Higgins and Richardson, 1999; Nathan, 2001; Johst et al., 2002; Doyle et al., 2003). The spatial distribution of mangroves on a regional and global scale has been studied extensively (e.g. Ridley, 1930; van der Pijl, 1969; Duke et al., 1998), and the determining role of dispersal in spatiotemporal changes of species distribution is a well-endorsed subject (Skellam, 1951; Duke, 1992; Clarke et al., 2001; Sousa et al., 2007). Some authors used marked propagules (i.e. dispersal units) to investigate dispersal distances (Yamashiro, 1961; Komiyama et al., 1992; Clarke, 1993; McGuinness, 1997; Breitfuss et al., 2003; Sousa et al., 2007; De Ryck et al., 2012). Though most propagules were found to disperse over only short distances (up to tens of meters), some propagules dispersed over extensive ranges. Clarke (1993), for example, recovered 3 Avicennia marina propagules at more than $10 \mathrm{~km}$ and 1 propagule at more than $50 \mathrm{~km}$. For Rhizophora mucronata, Komiyama et al. (1992) found a maximum dispersal distance of $1210 \mathrm{~m}$. Nevertheless, the dynamics and controlling factors of mangrove propagule dispersal have remained understudied, mostly due to the difficulty of the quantification of (long-distance) dispersal (Nathan, 2001). Such knowledge is, however, essential in defining realistic dispersal kernels and improving existing dispersal models, and thus for predicting the dispersal route of mangrove propagules. This knowledge may in turn improve the success of future restoration projects.

Mangrove propagules are hydrochorous, meaning that the hydrodynamics of tides and (ocean) currents constitute the dominant dispersal vector. Dispersal dynamics are further defined by the characteristics of the propagule itself, such as buoyancy, longevity and morphology (Tomlinson, 1994; Clarke and Myerscough, 1991; Clarke et al., 2001; Drexler, 2001; Allen and Krauss, 2006). Recently, Di Nitto et al. (2013) used a finite-volume advection-diffusion model to investigate the effect of these variables on the fate of dispersing propagules of the mangrove species Rhizophora mucronata Lamk., R. apiculata BL., Ceriops tagal (Perr.) C. B. Robinson and Avicennia officinalis L. in the PambalaChilaw Lagoon Complex (Sri Lanka). Until present, the study of Di Nitto et al. (2013) presents the only model that investigates mangrove propagule dispersal based on hydrodynamics and including trapping agents (retention by vegetation). Di Nitto et al. (2013) found that wind has a significant influence on the final distribution pattern of mangrove propagules, using a wind drag function of $3 \%$ wind speed on the surface currents in the model she applied. However, wind-induced dispersal was imposed uniformly on all species as a hydrodynamic component (Di Nitto et al., 2013) and consequently, though recognized to be important, species-specific differential behavior was not taken into account.

The role of prevailing wind conditions generally received only minor attention in existing hydrochorous dispersal studies, but those studies that are available point at the potential importance of species-specific effects. For example, for a set of non-mangrove seeds it was shown that seed transport and sorting by hydrochory is strongly influenced by wind, depending on the seed density and shape (Chambert and James, 2009). Stieglitz and Ridd (2001) investigated the dispersal of buoyant propagules of $R$. stylosa Griff., Bruguiera gymnorrhiza (L.) Lamk., Xylocarpus mekongensis Pierre and Heritiera littoralis Dryand. in the Normanby River estuary (Australia). Besides the main finding that the distribution of these propagules is characterized by a density-driven secondary circulation of water during the tropical dry season, windgenerated waves or wind drift seemed to have a negligible influence on their drift path (Stieglitz and Ridd, 2001). That is, despite their distinct shapes and sizes, especially the 'sail' of $H$. littoralis, propagules which enhance wind-driven dispersal (Tomlinson, 1994), the dispersal path within the estuary was found to be similar for all propagules (Stieglitz and Ridd, 2001).

This study aims at investigating the importance of morphological propagule traits and buoyancy behaviour in understanding the role of wind in hydrochorous mangrove propagule dispersal. This was studied by determining the dispersal behaviour of propagules under different hydrodynamic and wind conditions, both in a flume tank (controlled conditions), as well as in the field (natural conditions). We hypothesized that the influence of wind will be more pronounced for: (i) propagules with lower density; (ii) propagules with high surface roughness; and (iii) horizontally floating propagules compared to vertically oriented ones, in the case of elongated dispersal units. The main goal of our field experiment was to investigate the frequency distribution of dispersal distances under natural conditions as a first rough validation of the flume results. Knowing the dominant wind direction at the moment of the in situ experiment, we were able to study the role of wind in determining the shape of the dispersal distance distribution. Additionally, a collaboration was set up with local fishermen to get an idea of which species and how many propagules reach the open sea (Indian Ocean), and thus potentially start a long-distance dispersal journey.

\section{Methods}

\subsection{Studied species}

The hydrochorous propagules of $C$. tagal, $R$. mucronata, $H$. littoralis and of $X$. granatum Koen. (the fruit as a whole, as well as the separate seeds) were considered in this study (see Table 1), and are representatives of the most common mangrove propagule morphological types worldwide, with 
Table 1. Propagule characteristics and dispersal speed under various hydrodynamic and wind conditions. All values $\times 10^{-2} \mathrm{~m} \mathrm{~s}{ }^{-1}$.

\begin{tabular}{lcccccc}
\hline Species & H. littoralis & \multicolumn{2}{c}{ X. granatum } & R. mucronata & C. tagal \\
\hline Morphology & ellipsoidal & angular/pyramidal & "cannonball” & elongated & elongated & elongated \\
Floating orientation & $(-)$ & $(-)$ & $(-)$ & horizontal & horizontal & vertical \\
\hline
\end{tabular}

Position relative to water surface (dotted line)

\begin{tabular}{|c|c|c|c|c|c|c|c|}
\hline$n$ & & 10 & 8 & 1 & 20 & 20 & 20 \\
\hline Run/propagule & & 1 & 1 & 5 & 1 & 1 & 1 \\
\hline Mean length (cm) & & $(-)$ & $(-)$ & $(-)$ & $41.03 \pm 6.63$ & $24.38 \pm 2.68$ & $24.69 \pm 2.21$ \\
\hline Mean mass $(\mathrm{g})$ & & 33.11 & 46.80 & 892.72 & $65.70 \pm 16.39$ & $8.25 \pm 1.76$ & $8.27 \pm 1.36$ \\
\hline \multirow[t]{2}{*}{ Mean density $\left(\mathrm{g} \mathrm{L}^{-1}\right)$} & & $613.58 \pm 27.94$ & $870.66 \pm 27.89$ & 890.05 & $994.20 \pm 9.62^{\mathrm{a}}$ & $1001.80 \pm 8.47$ & $1023.28 \pm 4.88$ \\
\hline & WIND & & & & & & \\
\hline$v_{\mathrm{w}}=0 \times 10^{-2} \mathrm{~m} \mathrm{~s}^{-1}$ & $\mathrm{~S} / \mathrm{O}$ & $7.83 \pm 1.45^{\mathrm{b}}$ & $5.62 \pm 1.24^{\mathrm{b}}$ & $0.04^{\text {bd }}$ & $5.46 \pm 1.53^{\mathrm{b}}$ & $5.91 \pm 1.20^{\mathrm{b}}$ & $3.12 \pm 1.52^{\mathrm{b}}$ \\
\hline \multirow{3}{*}{$v_{\mathrm{w}}=15 \times 10^{-2} \mathrm{~m} \mathrm{~s}^{-1}$} & $\mathrm{~N}$ & $15.99 \pm 0.63$ & $15.68 \pm 1.27$ & $14.99 \pm 0.68^{\mathrm{c}}$ & $15.02 \pm 0.82^{\mathrm{b}}$ & $15.78 \pm 0.79$ & $15.70 \pm 0.41$ \\
\hline & $\mathrm{S}$ & $27.12 \pm 5.37$ & $20.92 \pm 0.65$ & $16.92 \pm 0.64^{\mathrm{c}}$ & $23.17 \pm 1.40$ & $24.29 \pm 0.86$ & $17.66 \pm 1.81$ \\
\hline & $\mathrm{O}$ & $(-)$ & $(-)$ & $(-)$ & $9.35 \pm 0.96^{\mathrm{b}}$ & $9.88 \pm 0.82$ & $13.77 \pm 1.51$ \\
\hline \multirow{3}{*}{$v_{\mathrm{w}}=30 \times 10^{-2} \mathrm{~m} \mathrm{~s}^{-1}$} & $\mathrm{~N}$ & $29.45 \pm 2.07$ & $29.56 \pm 0.91$ & $27.74 \pm 1.24^{\mathrm{c}}$ & $28.29 \pm 1.63^{\mathrm{c}}$ & $29.86 \pm 1.26$ & $30.03 \pm 0.58$ \\
\hline & $\mathrm{S}$ & $38.10 \pm 2.06$ & $33.91 \pm 1.06$ & $29.66 \pm 0.92^{c}$ & $32.72 \pm 0.90$ & $35.72 \pm 0.79$ & $30.74 \pm 1.28$ \\
\hline & $\mathrm{O}$ & $19.84 \pm 3.70$ & $26.06 \pm 0.44$ & $26.74 \pm 1.43^{\mathrm{b}}$ & $22.84 \pm 2.66$ & $26.98 \pm 1.32$ & $28.70 \pm 1.04$ \\
\hline
\end{tabular}

All values are averages over the distance range from $1 \mathrm{~m}$ to $4 \mathrm{~m}$, excluding the first and last meter. ${ }^{\mathrm{a}} n=18 ;{ }^{\mathrm{b}}$ mean over $3 \mathrm{rd}$ meter; ${ }^{\mathrm{c}}$ mean over 5 th meter; ${ }^{\mathrm{d}} 1$ propagule, 1 run

the exception of Avicennia marina (Forsk.) Vierh. type of propagule. We chose these species because $C$. tagal and $R$. mucronata (both Rhizophoraceae) are widely present in our study area and have typical viviparous propagules. Vivipary means that the embryo protrudes first from the seed coat and then from the fruit, while still attached to the parent tree (Tomlinson, 1994). The propagules of both these species are typically elongated (torpedo-shaped), of which C. tagal propagules are the smaller and more slender ones (Table 1). H. littoralis propagules (Sterculiaceae) were interesting to study because of their distinctive morphology, with a raised (dorsal) sail (Tomlinson, 1994) and very low density. They have a hydrophobic, woody epicarp and a fibrous mesocarp (Tomlinson, 1994). We added the cannonball-like fruits (i.e. 5 to 20 seeds encapsulated in a woody pericarp) as well as the angular-shaped seeds of $X$. granatum (Meliaceae) to our study, since both fruits and seeds of this species can disperse in the mangrove habitat, with the trees often lining mangrove channels. This species selection allowed us to investigate the role of wind in the dispersal of two distinct morphological groups of dispersal units: torpedo-shaped propagules of $C$. tagal and $R$. mucronata vs. ellipsoidal and angularshaped dispersal units for the propagules of $H$. littoralis and the seeds of $X$. granatum, respectively (see Table 1 ).

\subsection{Sample collection}

Mature and healthy propagules of $C$. tagal, R. mucronata and $X$. granatum, were (randomly) picked from adult trees to avoid exposure to the osmotic effects of tidal water after abscission. We consider propagules mature when (i) the cotyledon is bright reddish yellow (Ceriops) or brownish yellow (Rhizophora) and/or (ii) the propagule readily sheds from the tree when shaken. Lastly, freshly fallen $H$. littoralis propagules (seeds), were collected at neap tide under a parent tree in the high intertidal area.

The length, volume (using the water displacement method cf. Chave, 2005), mass and density of all propagules were measured and calculated before the start of the experiments. All propagules we used were checked for any damage that may modify surface roughness or significantly influence buoyancy behavior throughout the duration of the experiments.

\subsection{Flume study}

The importance of floating orientation in the quantification of the contribution of wind in hydrochorous dispersal was analyzed in a flume setup, using 20 horizontally and 20 vertically floating $C$. tagal propagules. We did not consider vertically floating propagules of $R$. mucronata here, since the length of the propagules exceeded the depth of the flume tank, thereby 


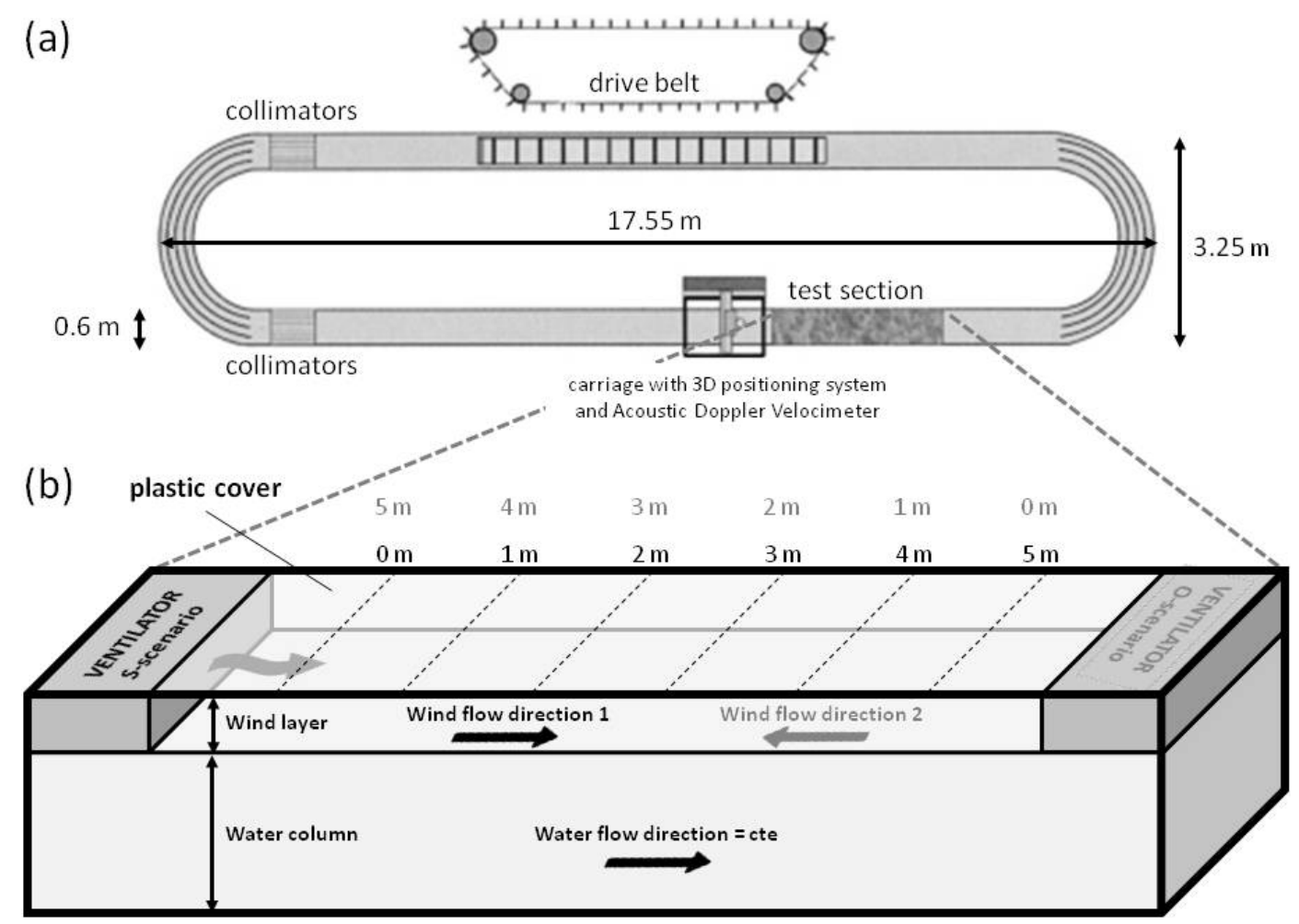

Fig. 1. Schematic representation of (a) the racetrack flume (modified from Bouma et al., 2005) and (b) a detailed depiction of the experimental flume section. (b) The position of the ventilator is indicated in dark grey (left: S-scenario; right: O-scenario). The wind flow direction 1 represents the $\mathrm{S}$-scenario (black arrows, numbers and text), where the O-scenario setup is shown as wind direction 2 (grey arrows, numbers and text). Dispersal time was measured at intervals of one meter (see dotted lines).

hampering vertical free flow. Furthermore, 20 horizontally floating $R$. mucronata propagules were used to look for differences between the dispersal speed of the two viviparous mangrove species, as well as 10 seeds of $H$. littoralis, and one fruit (unopened) and 8 individual seeds (after opening of the fruit) of $X$. granatum as the more compact counterparts of the two viviparous species.

Various hydrodynamic and wind conditions for mangrove propagule dispersal were simulated in a $17.5 \mathrm{~m}$-long and $0.6 \mathrm{~m}$-wide (Fig. 1a) oval race-track flume tank, which allowed for uniform flow conditions. The flume was filled with seawater (salinity of $34 \%$, temperature of $13.6^{\circ} \mathrm{C}$ and a water density of $1025.52 \mathrm{~g} \mathrm{~L}^{-1}$ ) and the water depth in the flume was kept constant at $0.35 \mathrm{~m}$. A uniform free-flow current velocity of $15 \times 10^{-2} \mathrm{~m} \mathrm{~s}^{-1}$ and $30 \times 10^{-2} \mathrm{~m} \mathrm{~s}^{-1}$ was generated with a conveyer belt. These velocities reflect natural water flow velocities in the studied mangrove creek (see field study), i.e. the Kidogoweni Creek (Kitheka et al., 2003). By using a smooth flume bottom, the water velocity gradient is steep (i.e. high currents at the bed because of low roughness). This simulates deeper water, where the upper decimeter of the profile has uniform current velocities.

For the wind experiment, an industrial ventilator was installed on top of the flume to create a wind layer over the water surface (Fig. 1b). Current velocities in all wind scenarios were calibrated to ensure water current velocities to be identical in all experimental scenarios (i.e. $15 \times 10^{-2} \mathrm{~m} \mathrm{~s}^{-1}$ and $30 \times 10^{-2} \mathrm{~m} \mathrm{~s}^{-1}$ ). To ensure a constant wind speed, a test section of $5 \mathrm{~m}$ in front of the ventilator was covered with a plastic roof and tested for leakage over the whole length of the experimental setup. The mean wind speed was $2.6 \pm 0.13 \mathrm{~m} \mathrm{~s}^{-1}$, which is the average of 3 wind speed measurements along the experimental setup $(0 \mathrm{~m}, 2.5 \mathrm{~m}$ and $5 \mathrm{~m})$. This wind speed was similar to the wind conditions at the moment of our field experiment (http://www.wunderground. com), and was measured using a velociCalc TSI anemometer (model 8384-M-GB). For both current velocities we applied an air flow in the same direction of the water flow (i.e., Sscenario), the opposite direction (i.e., O-scenario), as well as a scenario without wind (i.e., N-scenario) (Fig. 1).

Flow velocity measurements were taken before the start of each experiment by an Acoustic Doppler Velocimeter or ADV (Nortek AS, Oslo, Norway) placed on a 3D positioning system. The velocity data were stored using the Vectrino Plus Version 1.16 software programme (NIOZ, Yerseke, the Netherlands) connected with the ADV.

Propagules were consecutively released at location $0 \mathrm{~m}$ (Fig. 1b) along the flume tank, through a small fist-sized hole 
in the plastic cover, and traveling times were recorded using a stopwatch after passing each meter marking ( $0 \mathrm{~m}$ to $5 \mathrm{~m}$ ).

\subsubsection{Data analysis of flume experiment}

Mean dispersal velocities for each species were calculated using Matlab R2011b. To avoid perturbations in the velocity profile, due to the closeness to the ventilator for example, we excluded the first and last meter of the total experimental dispersal distance. For the $R$. mucronata propagules, only the 3rd meter was considered, after investigating whether or not the propagule was in equilibrium with the acting water and wind forces, based on the propagule velocity profiles. Due to its significantly higher density compared to the other dispersal units (Table 1), the X. granatum fruit needed more time (or dispersal distance) to reach a stable velocity (equilibrium of forces). Therefore the dispersal velocity for this dispersing unit was calculated only over the 5th meter of the section for the $\mathrm{N}$-scenario and $\mathrm{S}$ - scenario and over the 3 rd meter in the case of the O-scenario. The latter was decided as being the most representative dispersal velocity in this specific case, enabling the fruit to reach equilibrium with the moving water body, and precautionarily excluding possible instabilities (such as turbulent wind flow) in the last meter caused by the wind force acting in opposite direction.

\subsection{Field study}

The field study was conducted in the mangrove forest of Gazi Bay $\left(39^{\circ} 30^{\prime} \mathrm{E}, 4^{\circ} 26^{\prime} \mathrm{S}\right)$, a shallow, tropical coastal-water system located about $46 \mathrm{~km}$ south of Mombasa (Fig. 2). The total mangrove forest area is about $6.5 \mathrm{~km}^{2}$, comprising all 10 East African mangrove species: $R$. mucronata, C. tagal, A. marina (Forsk.) Vierh., Sonneratia alba J. Smith, B. gymnorrhiza, H. littoralis, X. granatum, Lumnitzera racemosa Willd., X. moluccensis (Lamk.) Roem, and Pemphis acidula Forst. (nomenclature according to Tomlinson, 1994). The region is drained by two tidal creeks, Kidogoweni in the northwestern part and Kinondo in the eastern part. While Kidogoweni Creek receives freshwater from the Kidogoweni River, Kinondo Creek lacks a direct freshwater input (Kitheka, 1996, 1997). River discharge is important during the wet season and occasionally reaches up to 5.0 and $17.0 \mathrm{~m}^{3} \mathrm{~s}^{-1}$ for the Kidogoweni and Mkurumuji Rivers, respectively (Kitheka, 1997). The bay experiences semi-diurnal tides with a tidal range of about $3 \mathrm{~m}$ (Obura, 2001) and an ebb-dominant asymmetry (Kitheka, 1996, 1997). From a (long-distance) dispersal perspective, it is crucial to note that the bay is open to the Indian Ocean through a relatively wide $(3500 \mathrm{~m})$ entrance in the south. Although a coral reef zone structurally separates the northern end of the bay from the Indian Ocean, the reef has a series of narrow channels and only emerges at low spring tide (Kitheka, 1996). Annual rainfall in Kenya has a bimodal distribution: the "long rains", coinciding with the southeast

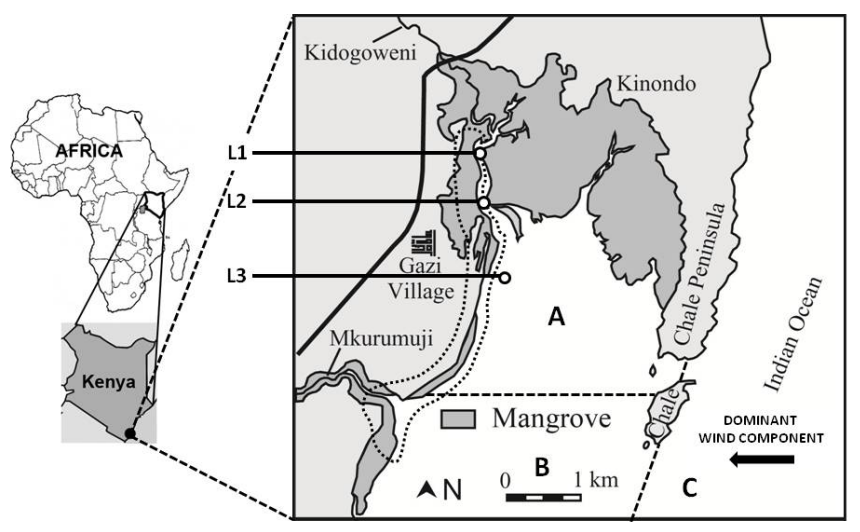

Fig. 2. Schematic depiction of our study area (Gazi Bay), with an indication of the three locations at which propagules were dropped in our field experiment (L1 to L3). The dotted contour represents the area where propagules were sought $12 \mathrm{~h}$ after having been released. The zones where local fishermen recovered propagules whilst fishing are indicated with A, B and C, separated by bold dotted lines.

monsoon (late March-July), and the "short rains", coinciding with the northeast monsoon (October-November) (Kenya Meteorological Department, Mombasa, Kenya). The wind is characterized by an eastern component and is predominantly onshore (Meteorological Department, 1964; EADAP, 1994).

On 27 February, 3 days after spring tide, three groups of 200 C. tagal and 100 R. mucronata propagules were released at three different locations (L1, L2 and L3) along the Kidogoweni Creek (Fig. 2), at the start of outgoing tide at L1 and L2 and at less than one hour later at L3. The different numbers of $C$. tagal and $R$. mucronata propagules per site reflect availability in the field at the moment of propagule collection. L1 and L2 are located in the center of the creek, whereas L3 is located $300 \mathrm{~m}$ offshore. In order to distinguish the propagules from each group and identify the original dropping location at the end of the experiment, we used white (non-toxic) waterproof paint to encode all propagules with one, two or three stripes, respectively. The white marks also increased the visibility and thus the number of propagules we found again after their release, especially in densely forested areas along the coastline (dark grey area within the dotted contour in Fig. 2) and in natural hydrodynamic traps where large amounts of organic material such as leaf litter accumulate. Furthermore, all propagules were given a number to facilitate easy processing of dispersal distance information.

After a period of $12 \mathrm{~h}$ (two ebb tides since the start of the experiment), we walked the entire southern coastline, starting $100 \mathrm{~m}$ upstream from dropping location L1 and ending about $300 \mathrm{~m}$ south of the Mkurumuji river mouth (dotted contour in Fig. 2). The limits of this area are based on the absence of painted propagules upstream and downstream of this region, using a buffer of $100 \mathrm{~m}$. We crossed the creek several times to screen parts of the eastern coastline, where 
no painted propagules were recovered. A Garmin GPSMAP 62 was used to determine the geographical coordinates of the location for each found propagule. We repeated this search one week later.

\subsubsection{Data analysis of field experiment}

The dispersal distance $d$ was calculated for each propagule using the spherical law of cosine and the obtained longitudelatitude data:

$d=\arccos \left[\sin \left(Y_{1}\right) \sin \left(Y_{2}\right)+\cos \left(Y_{1}\right) \cos \left(Y_{2}\right) \cos \left(X_{1}-X_{2}\right)\right] \cdot R,(1)$

with $\left(X_{1}, Y_{1}\right)$ and $\left(X_{2}, Y_{2}\right)$ the longitude and latitude of the stranding location and the dropping location, respectively, and $R=6370000 \mathrm{~m}$ being the earth's radius. Although this formula may underestimate the absolute dispersal distance of some propagules, ignoring the shape of the coastline and the creek's nonlinear shape (plan view), it yields a reliable proxy. Dispersal distance frequency plots were made subsequently for each dropping location separately.

\subsection{Fishermen data}

As a proxy for propagules that leave the system to the open ocean, and possibly start a long-distance dispersal journey, we asked local fishermen to keep a logbook. In this logbook they wrote down the amount of propagules they found in their nets, as well as the zone in which the recoveries were done. Three zones were delineated: within the bay (zone A), a transitional zone (zone B) and the Indian Ocean (zone C) (Fig. 1). However, observations were randomly gathered during their fishing trips. Consequently, we do not know which zones were screened at which date. These data are therefore only a rough indication of long-distance dispersal.

\section{Results}

\subsection{Flume study}

\subsubsection{Inter-specific differential effect of wind}

When no wind was added to the experimental setup, all propagules dispersed at almost the exact same speed as the water current (Fig. 3; Table 1). At the current speed of $30 \times 10^{-2} \mathrm{~m} \mathrm{~s}^{-1}$, only the dispersal speed of the horizontal $R$. mucronata propagules $\left(28.3 \times 10^{-2} \mathrm{~m} \mathrm{~s}^{-1}\right)$ and the $X$. granatum fruit $\left(27.7 \times 10^{-2} \mathrm{~m} \mathrm{~s}^{-1}\right)$ was on average slightly below the current velocity. As a consequence, the mean speed of horizontal C. tagal propagules was $1.57 \times 10^{-2} \mathrm{~m} \mathrm{~s}^{-1}$ higher than that of the horizontal $R$. mucronata dispersal units $(t=3.39, \mathrm{df}=38, p=0.002, n=40)$. In general, for all species, the detailed velocity profile showed an acceleration phase, which was proportionally more pronounced depending on the density of the dispersing unit (data not shown).
Nevertheless, this phase was negligibly short in all cases and consequently hard to detect in resulting figures (Fig. 4).

When wind was added, both in the same direction and opposite to the water flow, horizontally floating $C$. tagal and $R$. mucronata propagules showed quasi identical dispersal velocities, although C. tagal moved at a slightly higher speed in all cases using a $30 \times 10^{-2} \mathrm{~m} \mathrm{~s}^{-1}$ water flow velocity (Fig. 3, Table 1). The average speed of horizontal $C$. tagal propagules was $3 \times 10^{-2} \mathrm{~m} \mathrm{~s}^{-1}$ and $4.14 \times 10^{-2} \mathrm{~m} \mathrm{~s}^{-1}$ higher than for horizontal $R$. mucronata propagules, under the S-scenario $(t=11.23, \mathrm{df}=38, p<0.001, n=20)$ and O-scenario $(t=6.24, \mathrm{df}=38, p<0.001, n=20)$, respectively. These differences were smaller when the water flow velocity was set at $15 \times 10^{-2} \mathrm{~m} \mathrm{~s}^{-1}$, where horizontal $C$. tagal propagules on average moved at a speed of $1 \times 10^{-2} \mathrm{~m} \mathrm{~s}^{-1}$ (S-scenario; $t=3.04, \mathrm{df}=38, p=0.004, n=20)$ and $0.5 \times 10^{-2} \mathrm{~m} \mathrm{~s}^{-1}$ (O-scenario; $t=1.89, \mathrm{df}=38, p=0.066, n=20$ ) faster than the horizontal $R$. mucronata counterparts.

Although the results of $X$. granatum seeds were very similar to those of horizontally floating $C$. tagal and $R$. mucronata propagules, the $X$. granatum fruit seems to be least influenced by prevailing wind forces, dispersing at $16.92 \pm 0.64 \times 10^{-2} \mathrm{~m} \mathrm{~s}^{-1}$ under the S-scenario and at $15 \times 10^{-2} \mathrm{~m} \mathrm{~s}^{-1}$ current velocity. For $30 \times 10^{-2} \mathrm{~m} \mathrm{~s}^{-1}$ water speed, the $X$. granatum fruit dispersed at a speed of $29.66 \pm 0.92 \times 10^{-2}$ and $26.74 \pm 1.43 \times 10^{-2} \mathrm{~m} \mathrm{~s}^{-1}$ in the $\mathrm{S}$ - and O-scenario, respectively. The $H$. littoralis propagules are most influenced by prevailing wind conditions, dispersing at $38.10 \pm 2.06 \times 10^{-2} \mathrm{~m} \mathrm{~s}^{-1}$ in the S-scenario and at $19.84 \pm 3.70 \times 10^{-2} \mathrm{~m} \mathrm{~s}^{-1}$ in the O-scenario. If the water flow velocity was set at $15 \times 10^{-2} \mathrm{~m} \mathrm{~s}^{-1}$ and wind in the same direction was added to the system, $H$. littoralis propagules reached a mean velocity of $27.12 \pm 5.37 \times 10^{-2} \mathrm{~m} \mathrm{~s}^{-1}$. For the O-scenario and a $15 \times 10^{-2} \mathrm{~m} \mathrm{~s}^{-1}$ current velocity, both $H$. littoralis and $X$. granatum propagules showed a static behaviour or moved against the water flow.

Inter-specific differences most clearly follow from the scenario in which only wind was considered (no water current). In line with all other scenarios, the dispersal speed of $X$. granatum seeds $\left(5.62 \pm 1.24 \times 10^{-2} \mathrm{~m} \mathrm{~s}^{-1}\right)$ approaches that of horizontally floating $C$. $\mathrm{ta}^{-}$ gal $\left(5.91 \pm 1.20 \times 10^{-2} \mathrm{~m} \mathrm{~s}^{-1}\right)$ and $R$. mucronata $\left(5.46 \pm 1.53 \times 10^{-2} \mathrm{~m} \mathrm{~s}^{-1}\right)$ propagules. H. littoralis propagules are most influenced by prevailing wind, dispersing at $7.83 \pm 1.45 \times 10^{-2} \mathrm{~m} \mathrm{~s}^{-1}$, while the $X$. granatum fruit has a dispersal speed of $0.04 \times 10^{-2} \mathrm{~m} \mathrm{~s}^{-1}$, being influenced by the wind conditions only to a limited degree.

Figure 5 shows the increase of the dispersal speed $\Delta v(\%)$ for all propagules, for both the $15 \times 10^{-2} \mathrm{~m} \mathrm{~s}^{-1}$ (black) and the $30 \times 10^{-2} \mathrm{~m} \mathrm{~s}^{-1}$ (grey) water current velocity scenario, with $\Delta v(\%)$ calculated as

$\Delta v(\%)=\left(\frac{\bar{v}_{\text {prop }, \mathrm{S}}-\bar{v}_{\text {prop }, \mathrm{N}}}{\bar{v}_{\text {prop }, \mathrm{N}}}\right) \times 100$. 


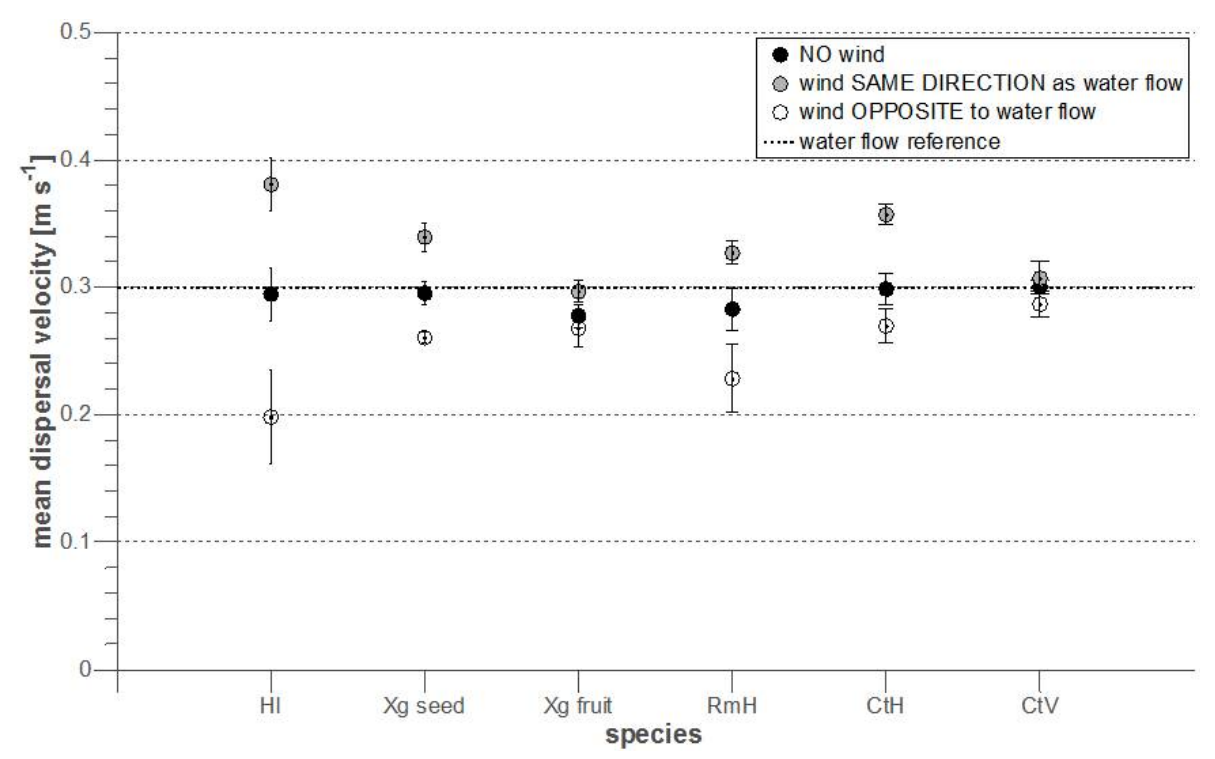

Fig. 3. Mean dispersal velocities for all species used in the flume study, for the $\mathrm{N}$-scenario (black circles), the S-scenario (grey circles) and the O- scenario (open circles). Vertical bars indicate standard deviations. The water flow velocity is added as a reference (dotted line). $\mathrm{Hl}$ : Heritiera littoralis propagules; Xg seed and fruit: seed and fruit of Xylocarpus granatum, respectively; RmH: Rhizophora mucronata propagules; $\mathrm{CtH}$ and $\mathrm{CtV}$ : horizontally and vertically floating Ceriops tagal propagules, respectively.
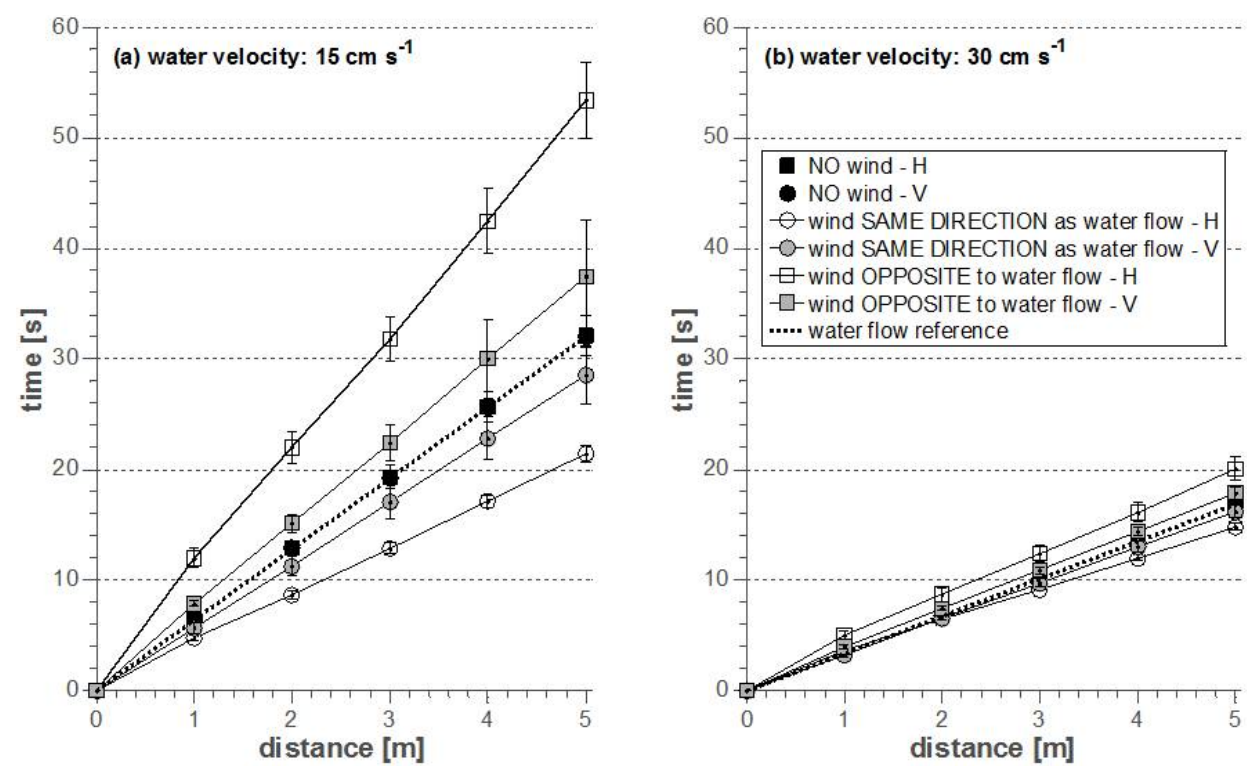

Fig. 4. Dispersal velocity profile of horizontally (open symbols, H) and vertically (grey symbols, $V$ ) floating Ceriops tagal propagules, for the S-scenario (circles), O-scenario (rectangles) and for the scenario in which was not considered (black symbols). The water flow velocity (dotted line) is added as a reference. All wind scenarios were tested using a water flow velocity of $15 \mathrm{~cm} \mathrm{~s}^{-1}$ (a), and $30 \mathrm{~cm} \mathrm{~s}{ }^{-1}$ (b). Vertical bars indicate standard deviations.

Herein, $\bar{v}_{\text {prop, S }}$ and $\bar{v}_{\text {prop, } \mathrm{N}}$ are the average dispersal velocity of the propagule under the S-scenario and the $\mathrm{N}$ scenario, respectively. The value of $\bar{v}_{\text {prop, } \mathrm{N}}$ is close to the water current velocity (see above). A general downward trend in the influence of wind with increasing density can be observed (e.g., negative slope of the trend lines) (Fig. 5). The slope of the trend line for the $15 \times 10^{-2} \mathrm{~m} \mathrm{~s}^{-1}$ water cur- rent velocity scenario is more negative than the one for the $30 \times 10^{-2} \mathrm{~m} \mathrm{~s}^{-1}$ scenario. Hence, the slope of the trend line is negatively correlated to the speed of the water current. Additionally, the difference between each datapoint (each dot in figure) and its projection on the trend line, from this point onward termed "residual", decreases with increasing water current velocity. 


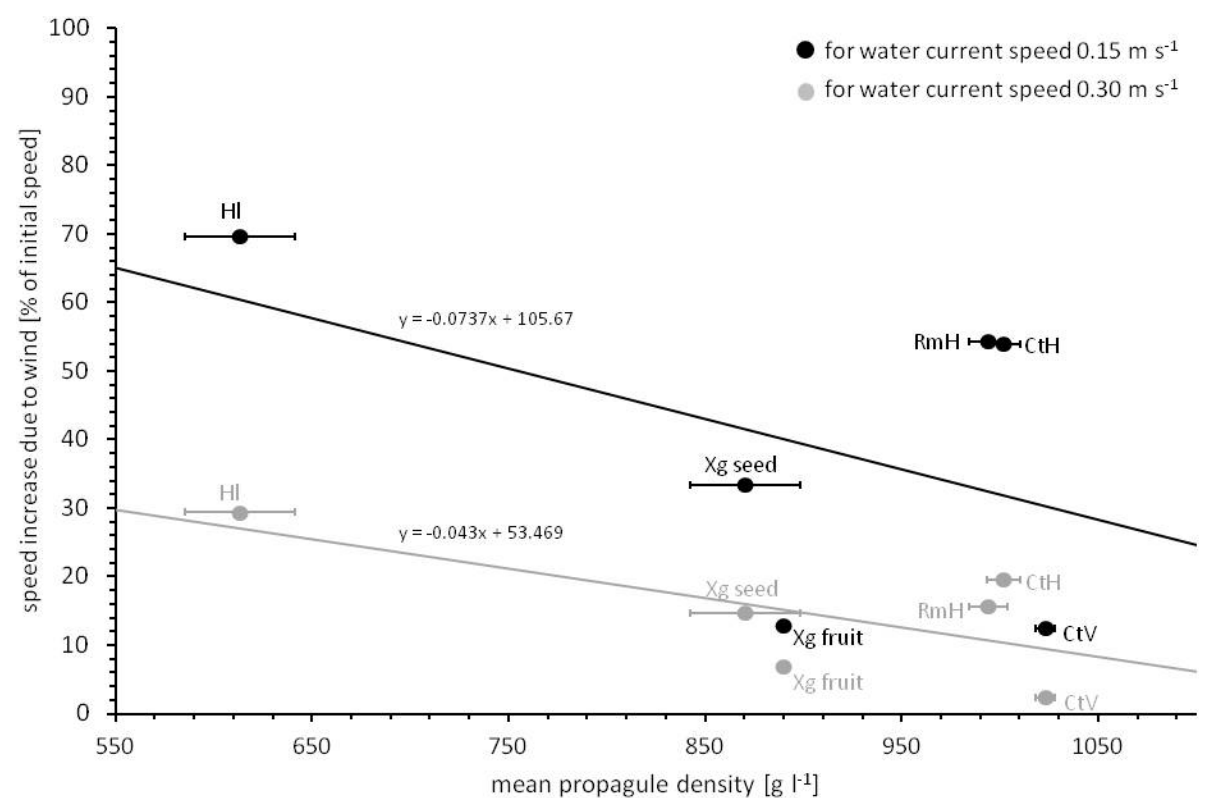

Fig. 5. Speed increase due to wind (only for the $\mathrm{S}$-scenario) in relation to propagule density, for a water current velocity of $0.15 \mathrm{~m} \mathrm{~s}{ }^{-1}$ (black) and $0.30 \mathrm{~m} \mathrm{~s}^{-1}$ (grey).

\subsubsection{Intra-specific differential effect of wind}

Intra-specific differences are negligible, which is shown by the low standard deviations of the results in Table 1. However, differences occur at the level of floating orientation, which can be seen both from Fig. 3 and Fig. 4, as well as the velocities in Table 1. From the data in Fig. 4 it follows that the horizontally floating propagules (open symbols) were significantly more influenced by equidirectional wind conditions than their vertically floating counterparts (grey symbols) $(t=$ $14.83, \mathrm{df}=38, p<0.001, n=20$ for the S-scenario; MannWhitney $U: p<0.001, n=20$ for the O-scenario). The role of wind appears to be less explicit when the water flow velocity was higher (Fig. $4 \mathrm{a}$ vs. Fig. $4 \mathrm{~b})(t=14.80, \mathrm{df}=38$, $p<0.001, n=20$ for the S-scenario; $t=-4.56, \mathrm{df}=38$, $p<0.001, n=20$ for the O-scenario). When no wind was added (black symbols), no significant differences existed among the horizontally and vertically floating propagules for a current velocity of $15 \times 10^{-2} \mathrm{~m} \mathrm{~s}^{-1}(t=0.45, \mathrm{df}=38$, $p=0.65, n=20)$ and $30 \times 10^{-2} \mathrm{~m} \mathrm{~s}^{-1}$ (Mann-Whitney $U$ : $p=0.65, n=20$ ), all floating at the same speed as the water.

\subsection{Field study}

Of the propagules dropped at L1, 22.5\% $(n=200)$ and $39 \%$ ( $n=100$ ) of the $C$. tagal and R. mucronata propagules were found back, respectively. For L2, recoveries reached $32.5 \%$ $(n=200)$ and $63 \%(n=100)$ of the released C. tagal and $R$. mucronata propagule batch, respectively, where for L3 this was $24 \%(n=200)$ and $50 \%(n=100)$. In total, for all dropping locations, $26.33 \%$ of $C$. tagal propagules $(n=600)$ and $50.67 \%$ of $R$. mucronata propagules $(n=300)$ have been recovered.

The dispersal distance distributions for the propagules of both species dropped at location L1, L2 and L3 are shown in Fig. 6. For L1, the mean dispersal distance for C. tagal propagules was $1156 \pm 170 \mathrm{~m}$ and $1217 \pm 211 \mathrm{~m}$ for $R$. mucronata propagules. No substantial inter-specific differences can be seen between the distribution in dispersal distances of both species (Fig. 6a). For the propagules dropped at L2, one can recognize two different distance ranges over which propagules dispersed (Fig. 6b): a first group (G1) of propagules with a shorter mean dispersal distance $(140 \pm 50 \mathrm{~m}$ for C. tagal and $189 \pm 63 \mathrm{~m}$ for $R$. mucronata) and a second group (G2) that dispersed much longer distances $(1871 \pm 236 \mathrm{~m}$ for $C$. tagal and $1683 \pm 203 \mathrm{~m}$ for $R$. mucronata) (Mann-Whitney $U: p<0.0001, n_{\mathrm{G} 1}=33$, $n_{\mathrm{G} 2}=94 ; 1$ outlier of $\mathrm{Ct}$ in $\mathrm{G} 2$ not taken into account). No significant difference exists among the dispersal shadow of both species (Mann-Whitney $U: p=0.0920, n_{\mathrm{Ct}}=64$, $n_{\mathrm{Rm}}=63$ ). The maximum dispersal distance was $2958 \mathrm{~m}$, reached by a $C$. tagal propagule (treated as an outlier, and hence not included in the calculation of the mean dispersal distance; outliers were detected using the two-sided Grubbs Test using a parameter value of 0.01 instead of 0.05 ). For L3, a scenario is observed similar to the L2 scenario, with two clearly distinct groups in terms of dispersal distance (MannWhitney $U: p<0.0001, n_{\mathrm{G} 1}=75, n_{\mathrm{G} 2}=23$ ) and no significant difference between the dispersal frequency distribution of both species (Mann-Whitney $U: p=0.11, n_{\mathrm{Ct}}=65$, $n_{\mathrm{Rm}}=63$ ) (Fig. 6c). The average dispersal distance of the first group was $861 \pm 97 \mathrm{~m}$ and $901 \pm 136 \mathrm{~m}$ for C. tagal 


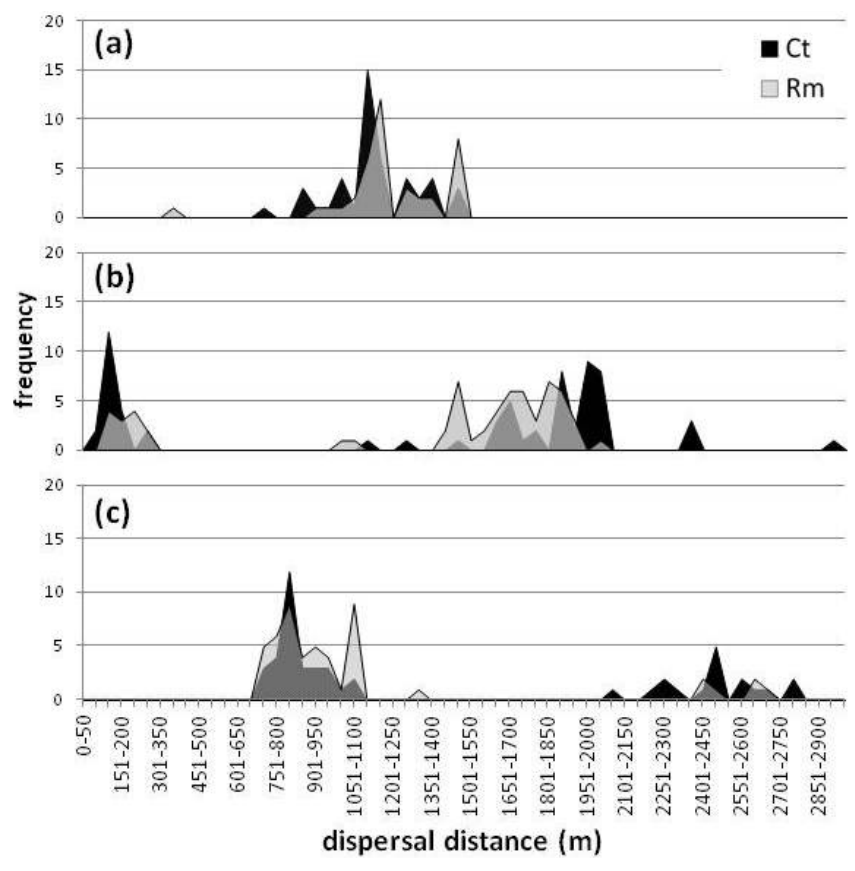

Fig. 6. Dispersal distance distribution (number of propagules) for Ceriops tagal (black) and Rhizophora mucronata (grey) propagules used in the release-recapture experiment in the field, for propagules dropped at location L1 (a); at location L2 (b); and at location L3 (c). Locations are indicated in Fig. 2.

and $R$. mucronata, respectively. Individuals of the second group reached more remote areas from the dropping location (L3), $2483 \pm 178 \mathrm{~m}$ for C. tagal and $2543 \pm 101 \mathrm{~m}$ for $R$. $m u$ cronata. The maximum dispersal distance here was $2783 \mathrm{~m}$.

Environmental settings where the propagules were recovered differ widely, though for L1 and L2, most propagules were recovered along the high-water line south-southwest of L2, and in an adjacent forest. While the propagules on the shore were concentrated near the high-water mark, the propagules in the forest were lying distributed over an area from the border of the creek up to about $90 \mathrm{~m}$ inland, lying mainly amongst roots of $R$. mucronata trees. Propagules dropped at L3 stranded on the beach, west of L3, up to the mouth of Mkurumuji River. Where the shore and beach mainly consist of bare sand, outcrops of fossil coral reef are quite extensive in some places. In these areas, propagules were collected in small pools in the dead coral's surface, under loose debris of old coral, behind fallen palm tree trunks and between extensive amounts of leaf litter in hydrodynamic traps near the high water mark.

\subsection{Fishermen data}

Within the bay (zone A), 4 and 19 propagules of C. tagal and $R$. mucronata were found, respectively. In the transition zone (zone B), 2 and 31 propagules, and in the Indian Ocean (zone C), 5 and 119 propagules of these species were found, respectively.

\section{Discussion}

To our knowledge, this is the first study to address the role of wind in hydrochorous mangrove propagule dispersal, focusing on propagule density and morphological characteristics of propagules, as well as on their floating orientation.

In the presence of wind, dispersal velocities significantly differed among species and buoyancy orientation of propagules. Thus, in agreement with our hypothesis (i) the influence of wind is more pronounced for dispersal units with a lower density. Propagules with a lower density will have a larger proportion of their volume above the water surface, which allows the wind force to exert more influence. $H$. littoralis propagules floating on the water surface are most influenced by prevailing wind conditions, yielding significantly higher velocities when the wind is equidirectional to the water current, but strongly limiting the dispersal range when the wind acts opposite or under a certain angle to the dominant water flow. Among elongated propagules, the density distribution of a propagule must be taken into consideration, since it determines the propagule floating orientation and thus indirectly the degree to which the fate of the propagule is influenced by the wind. This is consistent with our hypothesis (iii), that vertically oriented propagules are influenced significantly less than their horizontally floating counterparts. The surface roughness becomes gradually more important as the body of a propagule protrudes above the water surface. Therefore, hypothesis (ii) is rejected in the particular case where a significant part of a propagule's volume is submerged.

Thus, significant differences exist among species when studying the role of wind in hydrochorous mangrove propagule dispersal, which is especially interesting in metapopulation dynamics, genetic exchange and more specifically for defining dispersal kernels and dispersal model output.

\subsection{Flume study}

Our study answers the need for a better understanding of the dispersal mechanisms, which - along with establishment processes - present a valuable additive for existing (individual based or particle) models. Models, such as the FORMAN, KIWI and MANGRO model, constitute a standard (ecological) tool in modelling population dispersal (Werner et al., 2001). More specifically, they are being used to investigate the long-term evolution of Neotropical mangrove forest development, including the effects of natural and human-induced disturbances (e.g. Berger and Hildenbrandt, 2000; Doyle et al., 2003; Berger et al., 2006, 2008; Fontalvo-Herazo et al., 2011). Though these IBMs and 
the advection-diffusion hydrodynamic model of Di Nitto et al. (2013) are of great value in studying mangrove forest evolution and propagule dispersal, no particle-based model has been constructed in order to study the hydrochorous dispersal of mangrove propagules. Although it is assumed that finitevolume and particle tracking models should yield comparable results when properly used (Zhang and Chen, 2007), this study shows that, despite mangrove propagules being passive dispersal units, species-specific differential effects of wind on propagule dispersal exist. In collaboration with Deltares, knowledge from this study will be used in the Delft3D-PART model, allowing particles (mangrove propagules) to be followed as individuals (Lagrangian) with user-defined properties. This in order to improve dispersal modelling output from the Delft3D-WAQ model (Di Nitto et al., 2013) in which propagules were assumed to react similarly on wind conditions.

In our study, we investigated the dispersal behaviour of $C$. tagal and R. mucronata, as well as H. littoralis and X. granatum propagules, under various water flow velocities and wind conditions. When wind was ignored in the experimental setup, the dispersal velocity equaled the current speed for all species, which can be explained from a purely physical point of view, where energy is transferred to the propagule until equilibrium with the water body is reached. The time to reach this equilibrium depends both on the mass of the dispersing unit, as well as on the energy of the water flow. The latter may explain why, in the case of a $30 \times 10^{-2} \mathrm{~m} \mathrm{~s}^{-1}$ water flow velocity, the average velocity of $R$. mucronata dispersal units and the $X$. granatum fruit was lower than that of $C$. tagal propagules (Table 1), very likely being a direct consequence of the length of the test section $(5 \mathrm{~m})$, meaning that these dispersal units did not have the time to reach a steady state, where they did in the $15 \times 10^{-2} \mathrm{~m} \mathrm{~s}^{-1}$ water flow scenario. When wind was considered in the experiment, $H$. littoralis propagules were by far the most strongly influenced dispersal units, which follows directly from their low density, as well as the presence of a dorsal sail acting as a sail. This may be advantageous when the wind is parallel and in the same direction as the water flow, but strongly limits the dispersal range when wind is opposite or acts under a certain angle. In their study, Stieglitz and Ridd (2001) mentioned that wind drift seemed to have a negligible effect in the Normanby Bay at the moment of their observations. No details are given for the wind speed and direction in their study, but low wind speeds and/or differences in floating behavior might be explanatory. Floating capacity of propagules (buoyancy) evolves through time (unpublished data), changing the portion of the propagule above the water surface.

In order to compare morphological groups, we also considered $X$. granatum seeds. Though their size is most comparable to that of $H$. littoralis propagules, their dispersal speed values differ widely. This is explained by the higher density of $X$. granatum seeds compared to the lighter $H$. littoralis propagules and the absence of a sail. Where the latter float on top of the water column, the $X$. granatum seeds are submerged mostly, with only a small portion of the seed sticking out of the water body, and consequently catching less wind. The dispersal unit that was least influenced by the wind, was the $X$. granatum fruit. Its high mass requires more time to reach the equilibrium speed, but once this equilibrium state is reached, the wind has little influence on the small portion of the smooth and spherical surface that rises above the water surface.

The elongated propagules of $C$. tagal and $R$. mucronata showed comparable results, though the $R$. mucronata propagules on average were slightly slower due to a higher mass. An interesting difference was found between horizontally and vertically floating propagules of $C$. tagal, where in all experimental setups, the vertically oriented propagules were significantly less influenced by the acting wind forces.

In general, the influence of wind is negatively correlated with the propagule's density (Fig. 5). Nevertheless, the propagule's shape and surface roughness may not be ignored. The emerging surface of $X$. granatum fruits, for example, is part of a sphere with low surface roughness. Consequently, the wind has very little grip on its emerging surface. H. littoralis propagules, on the other hand, catch more wind, since an important part of their emerging volume (e.g., dorsal sail) extends in the z-direction (positive upward). The origin and magnitude of residuals can be explained from this point of view. The decrease of the trend line's slope in Fig. 5 with increasing water current velocity can be explained by the fact that the net force of wind on all propagules becomes relatively less important. Consequently, the species-specific differential effect of wind becomes less explicit, which is illustrated by the lower residuals. Although Fig. 5 assumes equidirectional wind and water conditions, the overall relation between density and the role of wind in hydrochorous dispersal will still hold in other scenarios where wind and water forces act under a different angle. From a physical perspective, a more pronounced species-specific differential effect would be expected if both forces act under an angle $\alpha=] 90,270[$, that is, all winds with a component that is opposite to the dominant water current.

While the dispersal of propagules, and the role of wind therein, has been treated uniformly in the hydrodynamic model of Di Nitto et al. (2013), the results of our study show that important differences exist among species, but also among individuals of the same species. In order to mathematically express species-specific dispersal velocities, further experiments are needed.

\subsection{Field study}

The dispersal range of propagules dropped at site L1 (Fig. 1) in the field all stranded in a range of 750 to $1500 \mathrm{~m}$ from the dropping location (Fig. 6a). This differs from the propagules dropped at L2 and L3 (Fig. 6b and c, respectively) where two distance ranges can be identified. This can be explained 
by the combination of the dominant easterly wind direction, and the presence of natural wind barriers. The creek is relatively narrow at L1, with a partial blocking of the wind by the mangrove forest, in contrast to L2 and especially L3, where the creek gradually widens and the wind can fully influence the route of the dispersing units. Knowledge from our flume study enables us to clarify the appearance of various distance ranges, assuming that for $\mathrm{L} 2$ and $\mathrm{L} 3$, the shorter distance range represents horizontally floating propagules, being directed landward by the easterly wind, while the vertically oriented propagules are less influenced by the wind and consequently strand in more remote areas.

Considering the wind conditions in our study area (estuary and strong shoreward winds), a high density (e.g. floating just under the water surface) is advantageous for longdistance dispersal, since the wind has less influence on submerged propagules and propagules therefore follow the water currents. Long distance is understood here as leaving the local mangrove biotope (enclosed bay), and reaching the open sea. For propagules with a lower density, surface roughness becomes additionally important, since these propagules have a higher volume sticking out of the water and their dispersal path is therefore more influenced by wind action. In this latter situation, the surface roughness is preferably minimal with respect to long-distance dispersal. Low density and high surface roughness will increase the susceptibility to the influence of wind, and increase the chance for the propagule to be blown towards the coast, and thus reduce its chances to leave the estuary. Among elongated propagules, vertically floating propagules are the most suitable candidates for long-distance dispersal in our field situation, being directed dominantly by tidal and ocean currents. Nevertheless, hydrodynamic and wind conditions in each study area must be studied carefully in relation to local landform (or topographic) characteristics, in order to determine which propagules are most advantageous in the context of long-distance dispersal. For example, low density, whether or not in combination with a high surface roughness, will very likely result in longer dispersal distances if the wind direction is parallel to or away from the coast. In general, we believe that floating, but fully submersed, propagules will be the best long-distance dispersers. However, to study successful long-distance dispersal more holistically, the buoyancy period and viability should also be considered.

\subsection{Fishermen data}

Although these data cannot be used to quantify long-distance dispersal, they indicate that propagules can leave the local mangrove system. This is especially clear from the amount of propagules that were found in the open ocean (zone C). Differences between $C$. tagal and R. mucronata may be explained by the mesh size, which could have been too large for the smaller $C$. tagal propagules. However, the discrepancy between the numbers of $C$. tagal and $R$. mucronata propag- ules is more likely caused by the presence of a much larger source population of $R$. mucronata in Gazi Bay (Neukermans et al., 2008).

\section{Conclusion}

Our study clearly indicates that the overall dispersal distances of hydrochorous mangrove propagules that leave the forest, thereby reaching open waters, are not only determined by prevailing hydrodynamic conditions but also by dominant wind forces, reflecting species-specific aspects. The degree to which wind determines a propagule's dispersal path depends on a combination of the propagule's density and floating orientation, as well as its morphology and surface roughness. The latter is especially important for propagules that have a significant part of their volume above the water surface (i.e., low propagule density). For example, $H$. littoralis propagules are easily steered by acting wind forces, with their dorsal sail, having a low density, thereby floating on the water surface. On the other hand, wind forces have a limited direct impact on $X$. granatum fruits, which are for the most part submerged due to their large density and have a smooth and spherical surface. For more elongated propagules, the floating orientation turns out to be even more important for dispersal. This follows directly from the observation of two distinct dispersal groups in our field experiments, suggesting that vertical propagules dispersed further than horizontal propagules, since the latter were most likely blown ashore by a dominant easterly wind. This can be fully explained by our wind experiments in a flume.

Density, floating orientation (density distribution), morphological and propagule surface characteristics should therefore be considered when quantifying the influence of wind in hydrochorous dispersal models.

Acknowledgements. This research was funded by the Flemish Interuniversity Council (VLIR), the "Vrije Universiteit Brussel" (VUB), the "Université Libre de Bruxelles" (ULB) and the Laboratorium of Plant Biology and Nature Management (APNA). T. Van der Stocken has a VLIR PhD Scholarship. D. De Ryck has a VUB assistant position. We sincerely thank our field assistant Hamisi Ali Kirauni and his fishermen for their support in the field. We also would like to thank Jared Bosire and James Gitundu Kairo from the Kenyan Marine Fisheries and Research Institute (KMFRI) for the logistical support in our travel to and from Kenya.

Edited by: S. Behara 


\section{References}

Allen, J. A. and Krauss, K. W.: Influence of propagule flotation longevity and light availability on establishment of introduced mangrove species in Hawaii, Pac. Sci., 60, 367-376, 2006.

Berger, U. and Hildenbrandt, H.: A new approach to spatially explicit modelling of forest dynamics: Spacing, ageing and neighbourhood competition of mangrove trees, Ecol. Model., 132, 287-302, 2000.

Berger, U., Adams, M., Grimm, V., and Hildenbrandt, H.: Modelling secondary succession of neotropical mangroves: Causes and consequences of growth reduction in pioneer species, Perspect. Plant Ecol., 7, 243-252, 2006.

Berger, U., Rivera-Monroy, V. H., Doyle, T. W., Dahdouh-Guebas, F., Duke, N. C., Fontalvo-Herazo, M. L., Hildenbrandt, H., Koedam, N., Mehlig, U., Piou, C., and Twilley, R. R.: Advances and limitations of individual-based models to analyze and predict dynamics of mangrove forests: A review, Aquat. Bot., 89, 260-274, 2008.

Bowne, D. R. and Bowers, M. A.: Interpatch movements in spatially structured populations: a literature review, Landscape Ecol., 19, 1-20, 2004.

Breitfuss, M. J., Connolly, R. M., and Dale, P. E. R.: Mangrove distribution and mosquito control: transport of Avicennia marina propagules by mosquito-control runnels in southeast Queensland saltmarshes, Estuar. Coastal Shelf S., 56, 573-579, 2003.

Cain, M. L., Milligan, B. G., and Strand, A. E.: Long-distance seed dispersal in plant populations, Am. J. Bot., 87, 1217-1227, 2000.

Caswell, H., Lensink, R., and Neubert, M. G.: Demography and dispersal: Life table response experiments for invasion speed, Ecology, 84, 1968-1978, 2003.

Chambert, S. and James, C. S.: Sorting of Seeds by Hydrochory, River Res. Appl., 25, 48-61, 2009.

Chave, J.: Measuring Wood Density for Tropical Forest Trees: A Field Manual for CTFS Sites, Universite Paul Sabatier, Toulouse, France, 2005.

Clarke, P. J.: Dispersal of grey mangrove (Avicennia marina) propagules in southeastern Australia, Aquat. Bot., 45, 195-204, 1993.

Clarke, P. J. and Myerscough, P. J.: Buoyancy of Avicennia marina propagules in South-Eastern Australia, Aust. J. Bot., 39, 77-83, 1991.

Clarke, P. J., Kerrigan, R. A., and Westphal, C. J.: Dispersal potential and early growth in 14 tropical mangroves: do early life history traits correlate with patterns of adult distribution?, J. Ecol., 89, 648-659, doi:10.1046/j.0022-0477.2001.00584.x, 2001.

Clobert, J., Baguette, M., Benton, T. G., and Bullock, J. M.: Dispersal ecology and evolution, Oxford University Press, 462 pp., 2012.

De Ryck, D. J. R., Robert, E. M. R., Schmitz, N., Van der Stocken, T., Di Nitto, D., Dahdouh-Guebas, F., and Koedam, N.: Size does matter, but not only size: Two alternative dispersal strategies for viviparous mangrove propagules, Aquat. Bot., 103, 6673, doi:10.1016/j.aquabot.2012.06.005, 2012.

Di Nitto, D., Erftemeijer, P. L. A., van Beek, J. K. L., DahdouhGuebas, F., Higazi, L., Quisthoudt, K., Jayatissa L. P., and Koedam, N.: Modelling drivers of mangrove propagule dispersal and restoration of abandoned shrimp farms, Biogeosciences, accepted, 2013.
Doyle, T. W., Girod, G. F., and Books, M. A.: Chapter 12: modeling mangrove forest migration along the southwest coast of Florida under climate change, in: Integrated Assessment of the Climate Change Impacts on the Gulf Coast Region, edited by: Ning, Z. H., Turner, R. E., Doyle, T. W., and Abdollahi, K., GRCCC and LSU Graphic Services, Baton Rouge, LA, 2003.

Drexler, J. Z.: Maximum longevities of Rhizophora apiculata and R. mucronata propagules, Pac. Sc., 55, 17-22, 2001.

Duke, N. C.: Mangrove floristics and biogeography, in: Tropical mangrove ecosystems, Coastal and estuarine studies series, American Geophysical Union, Washington, DC, 63-100, 1992.

Duke, N. C., Ball, M. C., and Ellison, J. C.: Factors influencing biodiversity and distributional gradients in mangroves, Global Ecol. Biogeogr., 7, 27-47, 1998.

Fontalvo-Herazo, M. L., Piou, C., Vogt, J., Saint-Paul, U., and Berger, U.: Simulating harvesting scenarios towards the sustainable use of mangrove forest plantations, Wetl. Ecol. Manag., 19, 397-407, 2011.

Higgins, S. I. and Richardson, D. M.: Predicting plant migration rates in a changing world: The role of long-distance dispersal, Am. Nat., 153, 464-475, 1999.

Johst, K., Brandl, R., and Eber, S.: Metapopulation persistence in dynamic landscapes: the role of dispersal distance, Oikos, 98, 263-270, 2002.

Kitheka, J. U.: Water circulation and coastal trapping of brackish water in a tropical mangrove-dominated bay in Kenya, Limnol. Oceanogr., 41, 169-176, 1996.

Kitheka, J. U.: Coastal tidally-driven circulation and the role of water exchange in the linkage between tropical coastal ecosystems, Estuar. Coast. Shelf S., 45, 177-187, 1997.

Kitheka, J. U., Ongwenyi, G. S., and Mavuti, K. M.: Fluxes and exchange of suspended sediment in tidal inlets draining a degraded mangrove forest in Kenya, Estuar. Coast. Shelf S., 56, 655-667, 2003.

Komiyama, A., Chimchome, V., and Kongsangchai, J.: Dispersal patterns of mangrove propagules - A preliminary study on Rhizophora mucronata, Res. Bull. Fac. Agr. Gifu Univ., 57, 27-34, 1992.

McGuinness, K. A.: Dispersal, establishment and survival of Ceriops tagal propagules in a north Australian mangrove forest, Oecologia, 109, 80-87, 1997.

Nathan, R.: The challenges of studying dispersal, Trends Ecol. Evol., 16, 481-483, 2001.

Nathan, R. and Muller-Landau, H. C.: Spatial patterns of seed dispersal, their determinants and consequences for recruitment, Trends Ecol. Evol., 15, 278-285, 2000.

Nathan, R., Perry, G., Cronin, J. T., Strand, A. E., and Cain, M. L.: Methods for estimating long-distance dispersal, Oikos, 103, 261-273, 2003.

Neukermans, G., Dahdouh-Guebas, F., Kairo, J. G., and Koedam, N.: Mangrove species and stand mapping in Gazi Bay (Kenya) using Quickbird satellite imagery, Spatial Science, 53, 75-86, 2008.

Obura, D. O.: Participatory monitoring of shallow tropical marine fisheries by artisanal fishers in Diani, Kenya, Marine Pollution Bulletin, 42, 64-78, 2001.

Pitelka, L. F., Gardner, R. H., Ash, J., Berry, S., Gitay, H., Noble, I. R., Saunders, A., Bradshaw, R. H. W., Brubaker, L., Clark, J. S., Davis, M. B., Sugita, S., Dyer, J. M., Hengeveld, R., Hope, G., 
Huntley, B., King, G. A., Lavorel, S., Mack, R. N., Malanson, G. P., McGlone, M., Prentice, I. C., and Rejmanek, M.: Plant migration and climate change, Am. Sci., 85, 464-473, 1997.

Ridley, H. N.: The dispersal of plants throughout the world, Reeve, Ashford, 292 pp., 1930.

Skellam, J. G.: Random Dispersal in Theoretical Populations, Biometrika, 38, 196-218, 1951.

Sousa, W. P., Kennedy, P. G., Mitchell, B. J., and Ordóñez L., B. M.: Supply-side ecology in mangroves: dor propagule dispersal and seedling establishment explain forest structure?, Ecol. Monogr., 77, 53-76, 2007.

Stieglitz, T. and Ridd, P. V.: Trapping of mangrove propagules due to density-driven secondary circulation in the Normanby River estuary, NE Australia, Mar. Ecol.-Prog. Ser., 211, 131-142, 2001.
Tomlinson, P. B.: The Botany of Mangroves, Cambridge University Press, Cambridge, 419 pp., 1994.

van der Pijl, L.: Principal of dispersal in higher plants, SpringerVerlag, Berlin, 161 pp., 1969.

Werner, F. E., Quinlan, J. A., Lough, R. G., and Lynch, D. R.: Spatially-explicit individual based modeling of marine populations: a review of the advances in the 1990s, Sarsia, 86, 411-421, 2001.

Yamashiro, M.: Ecological study on Kandelia candel (L.) Druce, with special reference to the structure and falling of the seedlings, Hikobio, 2, 209-214, 1961.

Zhang, Z. and Chen, Q.: Comparison of the Eulerian and Lagrangian methods for predicting particle transport in enclosed spaces, Atmos. Environ., 41, 5236-5248, 2007. 